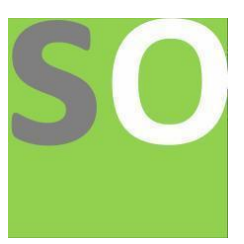

Article title: Living Things and their Environment Curriculum in Junior High School: Grade 10 Students' Perceptions and Experiences on its Pedagogical Appropriateness and Content

Authors: Alvin Jhon Manito[1]

Affiliations: Manlilisid National High School, Javier, Leyte, Philippines[1]

Orcid ids: 0000-0001-9894-420X[1]

Contact e-mail: alvinjhonmanito@gmail.com

License information: This work has been published open access under Creative Commons Attribution License http://creativecommons.org/licenses/by/4.0/, which permits unrestricted use, distribution, and reproduction in any medium, provided the original work is properly cited. Conditions, terms of use and publishing policy can be found at https://www.scienceopen.com/.

Preprint statement: This article is a preprint and has not been peer-reviewed, under consideration and submitted to ScienceOpen Preprints for open peer review.

DOI: 10.14293/S2199-1006.1.SOR-.PPCMWIF.v1

Preprint first posted online: 01 May 2021

Keywords: curriculum, pedagogical appropriateness, LTE content, student perception 
Article title: Living Things and their Environment Curriculum in Junior High School: Grade 10 Students' Perceptions and Experiences on its Pedagogical Appropriateness and Content

Author: Alvin Jhon Manito

Affiliation: Manlilisid National High School, Javier, Leyte, Philippines

ORCID iD: 0000-0001-9894-420X

Contact e-mail: alvinjhonmanito@gmail.com

License information: This work has been published open access under Creative Commons Attribution License

http://creativecommons.org/licenses/by/4.0/ which permits unrestricted use, distribution, and reproduction in any medium, provided the original work is properly cited. Conditions, terms of use and publishing policy can be found at https://www.scienceopen.com/

Preprint statement: This article is a preprint and has not been peer-reviewed, under consideration and submitted to ScienceOpen Preprints for open peer review.

Preprint first posted online: 01 May 2021

Keywords: curriculum, pedagogical appropriateness, LTE content, student perception 


\title{
Living Things and their Environment Curriculum in Junior High School: Grade 10 Students' Perceptions and Experiences on its Pedagogical Appropriateness and Content
}

\author{
Alvin Jhon C. Manito \\ Faculty, Manlilisid National High School, Javier, Leyte, Philippines
}

\begin{abstract}
The shifting of the recommended curriculum was legalized by Republic Act 1033 or the Enhanced Basic Education 2013. Unlike in the old curriculum that Biology was tackled in the Second year level, it was changed to Living Things and their Environment (LTE) and was found in all grade levels. The purpose of this study aims to know the perceptions and experiences of the Grade 10 students about the pedagogical appropriateness and content of the LTE curriculum at Manlilisid National High School (MNHS), Javier, Leyte. This study used mixed methods as its research design. Quantitatively, data were gathered using the NSES survey questionnaire, modified into Likert scale tool. It was distributed to 95 students, and the information was collected. Qualitatively, oral interviews and observations were also used to four students of the population. The respondents granted permission to the researcher to use the gathered data. Data were then analyzed using descriptive statistics for quantitative data, and thematic analysis for qualitative data. The results were compared and interpreted. Upon the analysis, various perceptions and experiences of the informant including positive and negative reactions on pedagogy and content were encountered which affect the attainment of the implemented curriculum.
\end{abstract}

Keywords: curriculum, pedagogical appropriateness, LTE content, student perception

\section{INTRODUCTION}

Many innovations had been seen in the new science program. One of which was the decongestion of the competencies and arrangement in spiral progression manner. In the previous Basic Education curriculum, a specific discipline was being designed in every grade level. First year will deal with integrated science, the second year will study with Biology, the third year will take up Chemistry, and the fourth year will master Physics. But in the new K12 science program, the various disciplines in science had been incorporated in every level namely Matter, Living Things and Their Environment (LTE), Force, Motion and Energy, and Earth and Space (Montebon, 2014).

Most of the researches recently primarily focus on the implementation of K-12 Science Program in a greater scale. Also, some previous researches talk Science education as a whole. But with the present study we can look into how well the Living Things and their Environment curriculum, one of the units in Science in Junior High School, is implemented by the teachers who are supposedly equipped with content knowledge and trained in the pedagogy of this subject matter.

Also, the need for this specific research is evident in the current limitation of a combined interpretation of quantitative and qualitative data regarding the evaluation of the subject matter that is being increasingly advocated for the teachers, students, and other related stakeholders. Accordingly, this study sought to provide data gathered from the students to implement the Living things and their Environment curriculum at its best as perceived also by the educators working within the curriculum. 
Quantitatively and qualitatively, we can get the perceptions and experiences of the Grade 10 students as they were able to undergo the topic since they were Grade 7 up to the present. The results of the study can help in evaluating the K-12 Program in the field of Science, the teachers on how they judiciously taught the subject matter, and the students, themselves, on how they perceived the course of study.

\section{Statement of the Problem}

This study aimed to determine the understanding of the Grade 10 students to Living things and their Environment curriculum's pedagogical appropriateness and content. Specifically, the study sought answer to the following questions:

1. What are the perceptions and experiences of the Grade 10 students to Living things and their Environment curriculum's pedagogical appropriateness in terms of achieving the goals of the Living Things and their Environment curriculum teaching and learning?

2. What are the perceptions and experiences of the Grade 10 students to Living things and their Environment curriculum's pedagogical appropriateness in relation to focusing on inquiry and activity as the basis of learning experiences?

3. What are the perceptions and experiences of the Grade 10 students to Living things and their Environment curriculum's pedagogical appropriateness in terms of using an effective instructional approach?

4. What are the perceptions and experiences of the Grade 10 students to Living things and their Environment curriculum's content?

\section{Significance of the Study}

The generalization of this present study would be a great contribution to the evaluation of the K-12 Program in a smaller scale, the Science teachers in realizing the content of the curriculum guide through their pedagogy, and the students through their perceptions and experiences as a tool to self-evaluate their learning, the processes and the curriculum materials in the entire Junior High School.

With this study, we can create interventions and strategies suitable to learning competencies which require exposure to direct and concrete experience to solidify the content knowledge and provide more scientific and logical setting to the students.

\section{Scope and Limitations of the Study}

This study is conducted in Junior High School to the three sections of Grade 10 at Manlilisid National High School, Javier, Leyte under the Division of Leyte from the month of December 2018 to January 2019. Each section is approximately composed of 40 students.

It only focuses on the perceptions and experiences of the Grade 10 students on the Living Things and their Environment curriculum in relation to its pedagogical appropriateness which encompasses strategies for building conceptual understanding, teaching science as inquiry and applying effective instructional strategies, and content. The study will not deal on the perceptions and experiences of the teachers by the time they were handling these students.

The study is only limited to the answers given by these students through the survey questionnaires, oral interviews, and the results of observations. 


\section{REVIEW OF RELATED LITERATURE}

The primary aim of the science curriculum is to produce scientifically literate citizens who are informed and active participants of the society, responsible decision makers, and apply scientific knowledge that will significantly impact the society and the environment. Specifically, the science curriculum is designed to enhance three learning domains of the students which require the students to be equipped with scientific processes and skills, understanding and applying scientific knowledge, and developing scientific attitudes and values. With the improvement of the different learning domains, it is the goal of the K-12 curriculum to produce students who are embodied with the following qualities Critical/creative problem solver, Responsible Steward of Nature, Innovative or inventive thinker, Informed Decision Maker and Effective communicator (K to 12 Curriculum Guide Science, 2016; Montebon, 2014).

Montebon (2014) also added that in terms of class instruction, the strategic curriculum point of view of the science program shifts from traditional methods of teaching to a more progressive and innovative exploration that highlights the enhancement of the students' higher order thinking skills and scientific literacy skills. The new curriculum utilizes learnercentered approach such as the inquiry based learning pedagogy and project work.

In this case, the formulation of a good question is a creative act, and at the heart of what doing science is all about (Chin and Osborne, 2007). And project work redresses this balance, by fostering a wide range of skills, allowing students to learn 'actively' and to take responsibility for and ownership of their ideas (Chamberlain, 2011). Concepts and skills are being taught by providing pedagogy which will enable them to enhance their cognitive, affective, and psychomotor domains (Montebon, 2014).

However, all activities must be firmly facilitated by the teacher since Kirschner et. al (2006) indicated that minimally guided instruction is less effective and less efficient than instructional approaches that place a strong emphasis on guidance of the student learning process. The advantage of guidance begins to recede only when learners have sufficiently high prior knowledge to provide "internal" guidance.

Moreover, Stocklmayer et. al (2010) also argued that there is a greater complementarity between formal school science education and the opportunities offered for science learning that are available outside of school, in what we will call the 'informal sector'. They believed that greater synergy between the two sectors can result in an enhanced science education for students at school.

While it would be difficult to transform the nature of science offered in most curricula, at least in the short term, such work does suggest that a better understanding of the attributes of science classroom activities that enhance 'task value' might make a significant contribution to how the quality of students' experience might be improved. It is somewhat surprising that so little work has been done in the context of science classrooms to identify what are the nature and style of teaching and activities that engage students (Osborne et. al, 2003). But with the new K to 12 Program recently implemented in the Philippines, teachers must reach out to the goals of the curriculum as what other countries are doing.

To illustrate, the study also of Jennifer Adams and Tanja Sargent in 2012 discussed the different perceptions of students in the curriculum change that happened in China. The Chinese government also made a move to change their curriculum from subject-centered to student-centered scheme. Their study showed that the curriculum change in China reduced the student stress level but increased in student participation. With these results gathered, it is 
assumed that the new curriculum entails a better way of learning for students since their perception of the curriculum has significantly shifted from the traditional to the new one.

The abovementioned studies primarily focus on the implementation of K-12 Science Program in a larger scale which include its goals, the vision to the graduates, the methods and strategies underlying in the new curriculum and the comparative status of the other countries implementing the same program. Also, some previous researches talk Science education as a whole. However in this current study we can look into how far the Living Thing and their Environment curriculum, one of the units in Science in Junior High School, is acted and realized by the teachers by its pedagogical appropriateness and content. In this study, we can visualize the realistic outcomes of $\mathrm{K}$ to 12 Science Education Program based on the perceptions and experiences of the students.

\section{Framework}

In accordance to the goals of the K to 12 Science Education Program, this research is theoretically anchored by Pragmatism of John Dewey in which it is based on two main principles. First, education should have a social function, and second, education should provide real-experiences to the child (Sharma et. al, 2018). Longo (2013) also added that when pragmatic attitude is applied to truth it yields beneficial outcomes for teachers and students.

\section{METHODOLOGY}

In this section, it discusses the research design, research instrument, sampling technique, research setting, participants, data gathering and analysis, ethical considerations and reflexivity.

\section{Research Design}

This study employed mixed methods as its research design. According to Creswell (2013), mixed method is a research approach in which researchers collect, analyse, and integrate both quantitative and qualitative data in a single study or in a sustained long-term program of inquiry to address their research questions.

\section{Research Instruments}

This study utilized the survey questionnaire, National Science Education Standards (NSES) survey instrument, which was patterned from the New Jersey Core Curriculum Content Standards (1996) implementing also the K to 12 Program and then modified into Likert scale tool (1-strongly disagree, 2-disagree, 3-neutral, 4-agree, and 5-strongly agree). Changes were made to some questions in order to make it specific and to conform to the research topic. The survey questionnaire was made up of twenty (20) perception questions which deal with the pedagogical appropriateness and content. The survey questionnaire was validated by Science teachers and instructors teaching research in college. The instrument was also pilot tested to the Grade 10 students, not part of the participants, to validate if the language used is appropriate to their grade level. Although survey questionnaire fits more on quantitative research, the data provided are also treated qualitatively. 
To support the methodological approach, interviews and observations were also done which is one of the most important sources of data to achieve the purpose of this study, that is, to determine and describe the opinions, thoughts and feelings of the Grade 10 Students of Manlilisid National High School regarding the Living Things and their Environment curriculum of the $\mathrm{K}-12$ Basic Education Program.

\section{Sampling and Research Setting}

This research used purposive sampling as the participants were purposely selected based on the criteria made by the researcher. Palys (2008) defined it as thinking of the person or place or situation that has the largest potential for advancing understanding, and looking there.

The study was conducted in Javier South District, Divison of Leyte at Manlilisid National High School (MNHS), Philippines under the K - 12 Basic Education Program. The place was chosen as the participants were available and the ease of accessibility of the place for the researcher was highly considered.

\section{Participants}

In this case, all three sections of Grade 10 students of MNHS were purposely selected in this study among all other grade levels. The criteria in choosing the participants include (1) they were done with all the learning competencies from Grade 7 up to the present compared with other grade levels in Junior High School, and (2) they had the capability of providing the necessary information for this study. This means that the choice of the participants fits most on the criteria of this research.

Ninety-five out of one hundred twenty (that is, $79.17 \%$ out of $100 \%$ ) Grade 10 students participated and completed the answering of survey questionnaires, while four (4) students from that population of different sections were interviewed.

\section{Data Gathering Procedure}

The data for the study were collected using questionnaire, oral interview and observations. The researcher has followed certain procedures in conducting the study. That is, (1) secure permit to conduct the study and parental consent letter. The permit to conduct the study was requested field to the office of the school head, while the parental consent letter was signed by the advisers who acted as in loco parentis. (2) The researcher formulated a survey questionnaire. It was fielded to three sections of Grade 10 at MNHS. Before the implementation of the survey questionnaire, it was considered that $75 \%$ and above in terms of the population in each section is present. The participants were also informed about their rights, and the nature of the study. The participants were given 20 minutes to answer the survey questionnaire. After that, it was collected. (3) Oral interview, on the other hand, to the respondents were conducted by pair, as they requested it. Only four students participated in the interview as the theoretical saturation was reached. (4) And simultaneously, observations were done during the answering of the survey questionnaire, and the conduct of the interview.

\section{Data Analysis}

Quantitatively, all information attained from the utilization of the survey questionnaire were organized and presented in the form of tables. It was analysed using descriptive 
statistics. Descriptive statistics is a method used to provide a brief summary of the samples and the measures done in a particular study. Basically, it is about describing what the numeric data have shown in tables or graphs (A Research Guide for Students).

Qualitatively, the results gathered from the oral interviews and observations were carefully treated and interpreted through thematic analysis. Thematic analysis is a process of identifying patterns or themes within qualitative data (Maguire and Delahunt, 2017). By using it, it is possible to link the various concepts and opinions of participants and compare them with the data gathered in different situation at different times from other or the same participants during the project. In this case, the potential for interpretation becomes infinite (Alhojailan, 2012).

\section{Ethical Considerations}

Before the implementation of the research instruments, informed consent was secured. Asking permission and informing the nature of the research to the school head, to the advisers and to the participants were also done. The participants were told that all information which will be gathered from the interview will be held confidential and will be only used for the purpose of the research conducted. They were reminded that there will be no harm for both parties. It was also understood to the respondents that their perceptions and experiences to the subject matter were voluntarily and genuinely expressed. Also, they knew that their participation in this research has no equivalent monetary incentives and the interview made was recorded using the phone.

\section{Reflexivity}

The researcher is one of the teachers teaching Grade 7 Science in Manlilisid National High School. However, he did not teach this batch of students during his stay in this institution. During the conduct of research, the researcher did not stand as a teacher in conducting the research in this institution, but instead as a researcher who is after with the information voluntarily given and expressed by the students.

\section{RESULTS AND DISCUSSIONS}

In this section, the data gathered has been tallied and computed. The percentage of the perceptions of the respondents in each area in pedagogical appropriateness and content in the questionnaires are determined and tabulated for descriptive statistics. Also in this section, the data gathered from the oral interviews and observations conducted are hereby interpreted and presented through thematic analysis.

\section{Pedagogical Appropriateness}

Table 1 shows the perception of the students on how the goals of the Living things and their Environment are addressed. The perception of the majority of the population of the students was neutral in relation to the focus of materials used by the teacher on concrete experiences with science phenomena $(\mathrm{N}=32,33.68 \%)$. This suggests that the students do not fully realize what they are learning in their science classes are connected. 
Table 1

Achieving the Goals of Living Things and Their Environment Curriculum Teaching and Learning

\begin{tabular}{|l|c|c|c|c|c|}
\hline \multicolumn{1}{|c|}{ KEY POINTS } & $\mathbf{1}$ & $\mathbf{2}$ & $\mathbf{3}$ & $\mathbf{4}$ & $\mathbf{5}$ \\
\hline $\begin{array}{l}\text { Focus on concrete experiences with } \\
\text { science phenomena }\end{array}$ & $11.57 \%$ & $4.21 \%$ & $\mathbf{3 3 . 6 8 \%}$ & $25.26 \%$ & $24.21 \%$ \\
\hline $\begin{array}{l}\text { Investigate important science concepts in } \\
\text { depth over an extended period of time }\end{array}$ & $13.68 \%$ & $9.47 \%$ & $13.68 \%$ & $\mathbf{3 4 . 7 3 \%}$ & $31.58 \%$ \\
\hline $\begin{array}{l}\text { Development of scientific reasoning and } \\
\text { problem-solving skills }\end{array}$ & $10.53 \%$ & $5.32 \%$ & $13.68 \%$ & $31.58 \%$ & $\mathbf{4 0 . 0 0 \%}$ \\
\hline $\begin{array}{l}\text { Stimulate students' interest and relate } \\
\text { science learning to daily life }\end{array}$ & $3.16 \%$ & $7.37 \%$ & $16.84 \%$ & $27.37 \%$ & $\mathbf{4 6 . 3 2 \%}$ \\
\hline $\begin{array}{l}\text { Build conceptual understanding through } \\
\text { logical sequence of related activities }\end{array}$ & $3.16 \%$ & $17.89 \%$ & $13.68 \%$ & $28.42 \%$ & $\mathbf{3 5 . 7 9 \%}$ \\
\hline $\begin{array}{l}\text { Assess student's prior knowledge and } \\
\text { experience }\end{array}$ & $3.16 \%$ & $10.53 \%$ & $10.53 \%$ & $27.37 \%$ & $\mathbf{5 3 . 6 8 \%}$ \\
\hline \multicolumn{2}{|l|}{ (1-strongly disagree, 2-disagree, 3-neutral, 4-agree, and 5-strongly agree) } \\
\hline
\end{tabular}

In other case, a great number of respondents agreed $(\mathrm{N}=33,34.73 \%)$ that they were able to investigate science concepts in an extended period of time. As noticed, they did not strongly agree with this item. This further implies that although an extended period of time for a lesson is given, it is still not enough for other students to understand. The lesson might be easy for the advanced students, while difficult to comprehend for the rest of the students.

However, among the items, students strongly agreed that their experiences from the previous levels and to the present developed their scientific reasoning and problem solving skills $(\mathrm{N}=38,40 \%)$. It supported by the fact that majority of them got an interest as their learning can be applied to real life setting $(\mathrm{N}=44,46.32 \%)$ which can help in building their conceptual understanding through logical sequence of activities $(\mathrm{N}=34,35.79 \%)$. The item which has the highest agreement perception is the review conducted by the teachers to assess their prior knowledge and experience $(\mathrm{N}=51,53.68 \%)$. This indicates that the primary part of the lesson plan in starting a new lesson is religiously executed by the teachers.

Table 2 focuses on inquiry and activity as the basis of learning experiences. The majority of the students had positive view regarding how they were engaged in the teaching-learning process in this field of science. Many of the students strongly agreed $(\mathrm{N}=31,32.63 \%)$ that they were engaged in the processes of science and along with it they were concentrated to scientific inquiries.

This further indicates that the maximum involvement of the students to the various activities employed by the teacher is evident.

Table 2

Focusing on Inquiry and Activity as the Basis of Learning Experiences

\begin{tabular}{|l|c|c|c|c|c|}
\hline \multicolumn{1}{|c|}{ KEY POINTS } & $\mathbf{1}$ & $\mathbf{2}$ & $\mathbf{3}$ & $\mathbf{4}$ & $\mathbf{5}$ \\
\hline $\begin{array}{l}\text { Focus on student inquiry and engage } \\
\text { students in the processes of science }\end{array}$ & $4.21 \%$ & $17.89 \%$ & $15.79 \%$ & $30.53 \%$ & $\mathbf{3 2 . 6 3 \%}$ \\
\hline $\begin{array}{l}\text { Provide opportunities for students to } \\
\text { gather and defend their own evidence } \\
\text { and express their results in a variety } \\
\text { of ways }\end{array}$ & $4.21 \%$ & $8.42 \%$ & $23.16 \%$ & $\mathbf{4 1 . 0 5 \%}$ & $33.68 \%$ \\
\hline
\end{tabular}


(1-strongly disagree, 2-disagree, 3-neutral, 4-agree, and 5-strongly agree)

In other areas, many of the students were convinced that they were given opportunities to present and defend the results of their study. That is, most of them agreed $(\mathrm{N}=39,41.05 \%)$.

Table 3 presents the use of effective instructional approach. Upon the analysis of the survey questionnaires, the item that yield the highest strongly agree response was the incorporation of effective strategies in assessing learning $(\mathrm{N}=39,41.05 \%)$. This means that the teacher used different assessment tools to check if the objective of the lesson is attained.

Table 3

Utilizing an Effective Instructional Approach

\begin{tabular}{|l|c|c|c|c|c|}
\hline \multicolumn{1}{|c|}{ KEY POINTS } & $\mathbf{1}$ & $\mathbf{2}$ & $\mathbf{3}$ & $\mathbf{4}$ & $\mathbf{5}$ \\
\hline $\begin{array}{l}\text { Balance of student-directed and teacher- } \\
\text { facilitated activities as well as discussion }\end{array}$ & $5.26 \%$ & $12.63 \%$ & $15.79 \%$ & $30.53 \%$ & $\mathbf{3 3 . 6 8 \%}$ \\
\hline $\begin{array}{l}\text { Incorporate effective strategies for the } \\
\text { teacher and/or students to use in assessing } \\
\text { student learning }\end{array}$ & $8.42 \%$ & $9.47 \%$ & $15.79 \%$ & $26.32 \%$ & $\mathbf{4 1 . 0 5 \%}$ \\
\hline $\begin{array}{l}\text { Integrating LTE with other areas of the } \\
\text { curriculum }\end{array}$ & $4.21 \%$ & $6.32 \%$ & $25.26 \%$ & $\mathbf{3 4 . 7 3 \%}$ & $24.21 \%$ \\
\hline $\begin{array}{l}\text { Opportunities to work collaboratively and } \\
\text { alone }\end{array}$ & $3.16 \%$ & $8.42 \%$ & $26.32 \%$ & $24.21 \%$ & $\mathbf{3 1 . 5 8 \%}$ \\
\hline
\end{tabular}

(1-strongly disagree, 2-disagree, 3-neutral, 4-agree, and 5-strongly agree)

Also, many students had the highest agree perception that there is an integration of LTE to other areas of the curriculum $(\mathrm{N}=33,34.73 \%)$. In terms of the balance of student and teacher-facilitated activities as well as discussion, many of the students strongly agreed $(\mathrm{N}=32,33.68 \%)$. In addition, these activities may include those opportunities to work collaboratively and alone which received strongly agree $(\mathrm{N}=30,31.58 \%)$ response to most of the students.

\section{LIVING THINGS AND THEIR ENVIRONMENT CURRICULUM CONTENT}

The result on students perception on the content of LTE curriculum revealed that many students agreed on most of the items such as the content is current and accurate $(\mathrm{N}=35$, $36.84 \%)$, emphasizes scientific inquiry which is actually the highest $(\mathrm{N}=47,49.47 \%)$, is appropriate for the grade level $(\mathrm{N}=41,43.16 \%)$, is free of bias $(\mathrm{N}=33,34.73 \%)$, and uses scientific vocabulary to facilitate understanding $(\mathrm{N}=37,38.95 \%)$. Furthermore, many students strongly agreed in few areas of the content such as the content addresses common misconceptions $(\mathrm{N}=29,30.53 \%)$, is using scientific language appropriately $(\mathrm{N}=34,35.79 \%)$, and is connected to society ( $\mathrm{N}=47,49.47 \%)$, the highest value among them. Generally, this indicates that most of the students agreed but not that convinced with the curriculum.

Table 4

Evaluation of the Living Things and Their Environment Curriculum Guide Content

\begin{tabular}{|l|c|c|c|c|c|}
\hline \multicolumn{1}{|c|}{ KEY POINTS } & $\mathbf{1}$ & $\mathbf{2}$ & $\mathbf{3}$ & $\mathbf{4}$ & $\mathbf{5}$ \\
\hline Current and accurately represented & $3.16 \%$ & $13.68 \%$ & $17.89 \%$ & $\mathbf{3 6 . 8 4 \%}$ & $24.21 \%$ \\
\hline Emphasize scientific inquiry & $3.16 \%$ & $6.32 \%$ & $18.95 \%$ & $\mathbf{4 9 . 4 7 \%}$ & $21.05 \%$ \\
\hline $\begin{array}{l}\text { Background materials address the science } \\
\text { content that is taught, as well as common } \\
\text { misconceptions. }\end{array}$ & $5.26 \%$ & $6.32 \%$ & $27.37 \%$ & $27.37 \%$ & $\mathbf{3 0 . 5 3 \%}$ \\
\hline
\end{tabular}




\begin{tabular}{|c|c|c|c|c|c|}
\hline Appropriateness for the grade level & $4.21 \%$ & $7.37 \%$ & $13.68 \%$ & $43.16 \%$ & $26.32 \%$ \\
\hline Free of bias & $14.74 \%$ & $9.47 \%$ & $23.16 \%$ & $34.73 \%$ & $11.58 \%$ \\
\hline $\begin{array}{l}\text { Writing style is interesting and engaging, } \\
\text { and scientific language is used } \\
\text { appropriately }\end{array}$ & $4.21 \%$ & $6.32 \%$ & $26.32 \%$ & $26.32 \%$ & $35.79 \%$ \\
\hline $\begin{array}{l}\text { Scientific vocabulary is used to facilitate } \\
\text { understanding rather than as an end in } \\
\text { itself. }\end{array}$ & $1.05 \%$ & $6.32 \%$ & $28.42 \%$ & $38.95 \%$ & $20.00 \%$ \\
\hline It is an enterprise connected to society. & $2.11 \%$ & $3.16 \%$ & $12.63 \%$ & $30.53 \%$ & $49.47 \%$ \\
\hline
\end{tabular}

\section{Strategies for Building Conceptual Understanding}

The respondents expressed their experience that there was one time, aside that the teacher brought real objects in the classroom, they were able to experience the topic such as visiting to a place, creating a quadrat, and identifying that place using a magnifying glass if that area is rich in biodiversity. When asked if they were able to get the objectives of the lesson, they defended that the objectives were attained.

The respondents added that upon the exploration experienced, it ensured lifelong learning which is very opposite if the lesson was taught in a chalk-talk manner. As they performed the activity, they were able to answer their questions in their minds prior to the conduct of the procedure. In this means, they were not pedagogically centered in assumptions and imagination, but in actual event.

Generally, in the Living things and their Environment curriculum, lessons must not be based on memorizing and knowing the ideas, but instead be based on new ways in doing the course of study. He suggested that, for instance, in a week there will be a mystery activity connected to the objective of the lesson so that students did not only learn but also they enjoy. The respondents advised that this subject matter must be more on activities to make it unforgettable. In this case, learning is evident as higher order thinking skills (HOT's) are observed along the process.

In the method, the respondents also said that one activity is not enough in building conceptual understanding but having another activity puts better understanding of the lesson.

The abovementioned experiences realized the goals of the $\mathrm{K}$ to 12 Science Education Program, that is, Living things and their Environment curriculum must be taught in a dynamic manner to ensure active learning. These results also support the theoretical lens of this research which is Pragmatism of John Dewey in which it is based on two main principles. First, education should have a social function, and second, education should provide real-experiences to the child (Sharma et. al, 2018). The experiences of the students as they went along to the subject were a starting point of being an active member of the society. In addition, Longo (2013) was also true of his view that when pragmatic attitude is applied to truth it yields beneficial outcomes for teachers and students. Teachers really taught, while students successfully learned.

\section{Connecting to the Outside World}

One of the respondents was still confused if he can use his learning to reason out scientifically the occurrence of some certain phenomena. However, another respondent 
argued that if ever they thought that the basic foundation of that situation was mastered, she can possibly solve the problem.

In terms of the usability of the lesson in daily setting, the respondent answered that he can hardly apply his learning if they were not able to experience it. They both agreed that the objects utilized before during the lesson remind them the content of the lesson. Then, that will be the time that they can use the lesson in their endeavour.

\section{Teaching Living Things and their Environment as Inquiry}

According to the respondents, inquiry in every activity is an integral part of the teachinglearning process. Although, some of the questions may arise upon performing the procedure, the strategic way of classroom instruction of allowing the students to perform first before answering the questions provides opportunity for them to build their own conceptual understanding. This is later on corrected during the discussion and generalization of the lesson.

In the discussion, there must be an interactive and collaborative effort between the teachers and the students. Both the teacher and the students must be given the opportunity to question and answer each other to maximize learning.

Although the majority of the students in Grade 10 agreed, the respondent said that during an activity the reporting of results is not always shown in the process. On the other hand, the gathering of evidences is primarily done through research, aside from the one observed. This will help in defending the results of the study.

\section{Effective Classroom Instructional Strategies}

The respondents emphasized that the review of the previous lesson plays a crucial role in the teaching-learning process. It serves as a springboard for the topic and with the new experience, the new lesson is better understood.

Importantly, they added that teachers in this subject must also participate and experience the lesson so that he will know how far the students realize the lesson. In the discussion, there must be a collaboration during the process. And in the assessment, they believed that students must be assessed differently.

Also based on their experience, the integration of other curriculum areas to Living things and their environment curriculum invites the students to engage in the various activities planned by the teacher. It is actually supported by their multiple intelligences, different learning styles and interests.

Moreover, working in groups and alone are also good ways of enriching and assessing learning. They emphasized that in group works the ideas related to the lesson are easily disseminated to one another as it is shared. It also builds teamwork. On the other hand, individual works allow the teachers to evaluate the students if they attain the objective of the topic.

\section{Development of Content}

It is exhibited that students did not strongly agree if the science content is current and accurately represented. The respondent explained that some of the teachers still rely on the old books and references as their sources of information. In addition, scientific inquiry may arise upon the presentation of the topic, but requires more sustainable and firm sources of information. 
In terms of addressing the science content as well as misconceptions, it is stated by the respondent that all of these things were carefully considered. From the previous grade levels, he added that the content of the curriculum guide for the Living things and their environment is appropriate to each grade level. They realized that in the spiral progression of the K-12 Program, some topics were repeated to connect it in the next grade level. At the same time, scientific language was also developed along the process.

The content in Living things and their Environment curriculum is not only used in school but also outside the school premises including dealing to others, to the environment and to yourself.

\section{View on the Curriculum}

Another thing that the respondents felt was that this unit is not given enough importance and interest, the way how other subject areas were taught. She added that mentors for this area treated the subject as easy to catch up for the students. The main reason pointed out by her was the one handling the unit is a teacher non-specializing in this field of science. In view of this, the respondent was worried if her experience on how the Living things and their Environment were taught is a good foundation if ever she proceeds in the Senior High School.

\section{COMPARATIVE DISCUSSIONS OF QUANTITATIVE AND QUALITATIVE DATA}

The findings for the pedagogical appropriateness were essential to realize how effective the implementation of curriculum was done. That is from recommended to written and then to strategic curriculum by the teachers in their class instruction. As mentioned by Montebon (2014) about class instruction, the strategic shifting from traditional methods of teaching to a more progressive exploration highlights the enhancement of the students' higher order thinking skills and scientific literacy skills, utilizing learner-centered approach such as inquiry based learning pedagogy.

This is true to the findings of this research since quantitatively the perception of the majority of the students strongly agreed that their experiences developed their scientific reasoning and problem solving skills $(\mathrm{N}=38,40 \%)$, supported by the fact that majority of them got an interest as their learning experiences can be applied to real life setting $(\mathrm{N}=44$, $46.32 \%$ ). However, students was neutral concerning the focus of materials on concrete experiences with science phenomena $(\mathrm{N}=32,33.68 \%)$. Qualitatively, it was also proven as the respondents confirmed that they were exposed to real life setting such as identifying the biodiversity present in a quadrat. This provides them an unforgettable life-long learning experience.

In relation to this learning experience, Stocklmayer et. al (2010) also suggested that the 'informal sector' can help in an enhanced science education for students at school. Project work can also foster a wide range of skills, allowing students to learn 'actively' and to take responsibility for and ownership of their ideas (Chamberlain, 2011). Because in such times that it is not enough, students will be confused if he can use his learning to reason out scientifically the occurrence of some certain phenomena as what the respondent said.

The respondents also added and said that one activity is not enough in building conceptual understanding but having another activity puts better understanding of the lesson. The quantitative data agreed $(\mathrm{N}=33,34.73 \%)$ that they were able to investigate science concepts in an extended period of time. On the other hand, a different interpretation was observed in building their conceptual understanding through a sequence of related activities as many of the students strongly agreed $(\mathrm{N}=34,35.79 \%)$. 
The majority of the students had positive view regarding their engagement in the processes of science with scientific inquiries. As a support, many of the students strongly agreed $(\mathrm{N}=31,32.63 \%)$. As what the respondent explained, inquiry is indispensable in the teaching-learning process. Through this, it provides opportunity for them to build their own conceptual understanding. This information conforms to the statement of Chin and Osborne (2007) that the formulation of a good question is a creative act, and at the heart of what doing science is all about. In fact, many of the students were convinced that they were given opportunities to present and defend the results of their study. That is, most of them agreed $(\mathrm{N}=39,41.05 \%)$. Furthermore, many students strongly agreed $(\mathrm{N}=32,33.68 \%)$ in connection to the balance of student and teacher-facilitated activities as well as discussion. Based on the statement of the respondent, collaboration in the discussion must be fair. Both the teacher and the students must be given the opportunity to question and answer each other to maximize learning.

In addition, these activities may include those opportunities to work collaboratively and alone which received strongly agree $(\mathrm{N}=30,31.58 \%)$ response to most of the students. The respondents said that working in groups and alone are also good ways of enriching and assessing learning. But there must be the presence and guidance of the teacher. As what Kirschner et. al (2006) indicated, minimally guided instruction is less effective and less efficient than instructional approaches that place a strong emphasis on guidance of the student learning process.

As what the respondent emphasized, review of the lesson in the presence of a teacher is a springboard for the topic and with the new experience, the new lesson is better understood. $\mathrm{He}$ added that teachers must also participate and experience the lesson, and assess the students differently. This is true as it obtained a strongly agree response to the incorporation of effective strategies in assessing learning $(\mathrm{N}=39,41.05 \%)$, and in assessing their prior knowledge and experience $(\mathrm{N}=51,53.68 \%)$.

According to Osborne et. al, (2003) it is somewhat surprising that so little work has been done in the context of science classrooms to identify what are the nature and style of teaching and activities that engage students. As what the respondent said it must be based on new ways in doing the course of study. He added that curriculum integration increases the participation of the students. Fortunately, many students had the highest agree perception that there is really an integration of LTE to other areas of the curriculum experienced $(\mathrm{N}=33$, $34.73 \%)$.

In terms of the content of LTE curriculum, it is found out that many students agreed on most of the items such as the content is current and accurate $(\mathrm{N}=35,36.84 \%)$, emphasizes scientific inquiry which is actually the highest $(\mathrm{N}=47,49.47 \%)$, is appropriate for the grade level $(\mathrm{N}=41,43.16 \%)$, is free of bias $(34.73 \%)$, and uses scientific vocabulary to facilitate understanding $(\mathrm{N}=37,38.95 \%)$. Based on the response during the interview, some of the teachers still rely on the old books and references as their sources of information. In addition, scientific inquiry may arise upon the presentation of the topic, but requires more sustainable and firm sources of information.

Also they realized that in the spiral progression of the K-12 Program, some topics were repeated to connect it in the next grade level. At the same time, scientific language was also developed. In this process, many students strongly agreed in few areas of the content such as the content addresses common misconceptions $(\mathrm{N}=29,30.53 \%)$, is using scientific language appropriately ( $\mathrm{N}=34,35.79 \%)$, and is connected to society $(\mathrm{N}=47,49.47 \%)$, the highest value among them. Hence, it must take an extra effort to yield the same result as what the study of Adams and Sargent (2012) assumed that the new curriculum entails a better way of learning 
for students since their perception of the curriculum has significantly shifted from the traditional to the new one.

\section{CONCLUSION}

The perceptions and experiences of the Grade 10 students to LTE curriculum's pedagogical appropriateness in terms of achieving the goals of the LTE curriculum teaching and learning (neutral to strongly agree), focusing on inquiry and activity as the basis of learning experiences (agree to strongly agree), and using an effective instructional approach (agree to strongly agree) gained a positive view from the Grade 10 students ranging from neutral to strongly agree response. The same perceptions and experiences were received by the LTE curriculum content which ranges from agree to strongly agree response. Although the respondents suggest for improvements and innovations, it has a little effect to the overall perceptions of the population, but requires immediate attention.

In a general sense, it can be deduced that students are viewing the new curriculum beneficial to them through their perception in this study. With this positive perception of students, LTE curriculum is moving to be on the right track. If the teachers continue to eagerly implement the $\mathrm{K}$ to 12 program the success of the program could be ensured. With the collaboration of the stakeholders, the new curriculum could work for the betterment of the country.

\section{RECOMMENDATIONS}

The following recommendations are derived from the findings and conclusions.

- The goal of the K to 12 Science Education Program must be continually implemented and realized.

- Teachers must be flexible enough in thinking more strategic ways of teaching the students in a variety of ways allowing these students to explore the natural world if available by all means as long as they are safe and secured.

- Teachers must do put an extra effort in mastering the lesson, especially if it is not the field of specialization. To overcome such, "Team Teaching" may apply depending on the availability of the Science major teachers in each field in an institution completing the four areas of the Science curriculum units.

The study used mixed methods which focused only on the perceptions and experiences of the Grade 10 students on the LTE curriculum in relation to its pedagogical appropriateness, and content.

However, this study is subject to different limitations. This study is only administered to ninety-five (95) students and this number could not be used to represent the whole perception of Grade 10 students taking LTE curriculum in the Philippines. And, the instrument was conducted in the rural areas which does not signify the same perception with those students in the urban areas. It means that further research is expected to these aspects and the other curriculum areas of the $\mathrm{K}$ to 12 Science Education Program if the same findings may result. Also, the study focused more on the students as the participants which means that the perceptions and experiences of the teachers were not fully involved and covered in this research. 


\section{References}

Adams, J. \& Sargent, T. C. (2012) Curriculum Transformation in China: Trends in Student Perceptions of Classroom Practice and Engagement (Working Paper). Gansu Survey of Children and Families.

Alhojailan, M.I. (2012), Thematic Analysis: A Critical Review of its Process and Evaluation. West East Journal of Social Sciences, 1(1)

Chamberlain, M. (2011). Promoting Enquiry and Active Learning Through Project Work, Bioscience education

Chin, C. and Osborne, J. (2008). Students' questions: a potential resource for teaching and learning science. Studies in Science Education, 44(1), 1-39. Retrieved from http://www.informaworld.com

Creswell, J.W. (2013), Steps in Conducting a Scholarly Mixed Methods Study. DBER $\begin{array}{lllll}\text { Speaker } & \text { Series } & \text { Series } & \text { 48. } & \text { Retrieved }\end{array}$ http://digitalcommons.unl.edu/dberspeakers/48

Department of Education K to 12 (2016).K to 12 Curriculum Guide Science (Grade 3 Grade 10)

Kirschner, P.A., Sweller, J. and Clark, R.E. (2006). Why Minimal Guidance During Instruction Does Not Work: An Analysis of the Failure of Constructivist, Discovery, Problem-Based, Experiential, and Inquiry-Based Teaching. Educational Psychologist, 41(2), 75-86, DOI: 10.1207/s15326985ep4102_1

Longo, G. (2013), Pragmatism and Teaching Philosophy: An Inquiry into truth, Relativism and Practice. Master's Thesis

Maguire, M. and Delahunt, B. (2017). Doing a Thematic Analysis: A Practical, Step by Step Guide for Learning and Teaching Scholars. 3(1)

Montebon, D.R. (2015). K12 Science Program in the Philippines: Student Perception on its Implementation. International Journal of Education and Research, 2(12). Retrieved from https://www.researchgate.net/publication/280234350

New Jersey Core Curriculum Content Standards in science (1996). Chapter 4: Analyzing and Selecting Science Curriculum Materials, New Jersey Science Curriculum Framework

Osborne, J., Simon, S. \& Collins, S. (2003). Attitudes towards science: A review of the literature and its implications. International Journal of Science Education, 25(9), 1049-1079, DOI: 10.1080/0950069032000032199

Palys T. (2008). Purposive sampling. In L.M. Given (Ed.). The Sage Encyclopedia of Qualitative Research Methods. (Vol. 2). Sage: Los Angeles , 697-8.

Sharma, S., Devi, R. and Kumari, J. (2018). Pragmatism in Education. International Journal of Engineering Technology Science and Research. 5(1)

Stocklmayer, S.M., Rennie, L.J. and Gilbert, J.K. (2010). The roles of the formal and informal sectors in the provision of effective science education. Studies in Science Education, 46(1), 1-44 